RESEARCH REPORT

\title{
Unintentional and violent injuries among pre-school children of teenage mothers in Sweden: a national cohort study
}

\section{Cecilia Ekéus, Kyllike Christensson, Anders Hiern}

J Epidemiol Community Health 2004;58:680-685. doi: 10.1136/jech.2003.015255

See end of article for authors' affiliations

Correspondence to Dr C Ekéus, Department of Public Health Sciences, IHCAR, Karolinska Institute, 17176 Stockholm, Sweden: cecilia_ekeus@yahoo.com

Accepted for publication 10 December 2003

\begin{abstract}
Study objective: This study investigates the risk and mediating mechanisms of unintentional and violent injuries in pre-school children of teenage mothers.

Design: Cohort study based on Swedish national registers. Cox analyses of proportional hazard were used to estimate the relative risk of hospital admission and death attributable to injuries in analyses of data from national registers.

Participants: The study population was a national cohort of 800192 children born in Sweden during 1987-93 who were followed up prospectively from birth to their 7th birthday.

Main results: Children of teenage mothers had higher relative risks (RRs) of hospital admissions for violent as well as unintentional injuries; age adjusted RRs of $2.7(95 \% \mathrm{Cl} 1.2$ to 6.1$)$ and 1.6 (1.4 to 1.8), respectively, for children of mothers under 18 years of age and 2.5 (1.6 to 3.8$)$ and 1.5 (1.4 to 1.6) of mothers aged 18-19 are compared with those with mothers aged at least 32 at the birth of the child. When the models were adjusted to socioeconomic variables and indicators of parental substance misuse and psychiatric illness the risk decreased slightly but remained well above that of children with older mothers. In addition, children of teenage mothers had an increased risk of death attributable to violent injuries (RR 6.7 (2.6 to 16.0), as well as to unintentional injuries (RR 3.5 (2.0 to 6.1).

Conclusions: Maternal age is an important determinant of injuries in pre-school children in Sweden and the children of teenage mothers are at particular risk. Young parents should be given priority in injury prevention programmes.
\end{abstract}

Sweden. All children born in Sweden during 1987-93 were identified in the Swedish Medical Birth Register (SMBR) as well as the age and personal identification number of the mother, number of siblings, family situation, geographical location of the home, and the date of birth and sex of the child. The identity of the mother was determined in 800190 (99\%) of the 809220 children registered as live born in the SMBR during 1987-93. These are the children included in the study population.

The biological father was identified in $99.4 \%$ of the study population ( $97.9 \%$ of the children with teenage mothers) and the maternal grandmother in $91.0 \%$ (91.9\% of the children with teenage mothers) in a linkage with the Swedish Multigeneration Register through the unique personal identification numbers of the child and the mother.

\section{Socioeconomic variables}

The following sociodemographic variables were linked to each child:

- Socioeconomic status (SES) of the household was identified in the Swedish Population and Housing Census of 1990. Socioeconomic groups were defined according to a classification used by Statistics Sweden, which is based on occupation but also take educational level of occupation, type of production, and position at work of the head of the household into account. ${ }^{10}$ To increase the comparability between different age groups in terms of SES we used grandmaternal SES, as most people in Sweden do not establish themselves on the labour market before 20 years of age.

Abbreviations: SES, socioeconomic status; SMBR, Swedish Medical Birth Register
This study was based on Swedish national registers kep by the National Board of Health and Welfare and Statistics 
- country of birth of the grandparents (Register of the Total Population),

- social welfare benefits received by and disposable income (in quartiles) of the maternal grandmother (Sweden's Total Enumeration Income Survey, 1990)

- education of maternal grandmother (the Swedish Register of Education, 1990)

- housing (type of residence) of the mother (Swedish Population and Housing Census, 1990)

\section{Psychiatric illness, addiction, and foster care among parents}

Risk factors related to psychiatric illness and addictions among the biological parents were obtained through individual record linkage to the Swedish Hospital Discharge Register for the years 1987-2000. The variables were defined according to the 9th revision of the WHO International Classification of Diseases (ICD-9) during 1987-96 and the 10th revision of the WHO International Classification of Diseases during 1997-2000;

- Any psychiatric disorder: a main diagnosis of 290-319 (ICD-9) and F00-F09, F17, and F20-99 (ICD-10) in 19972000.

- Substance misuse: a main or contributory diagnosis of 292, 304, 965.0, 968.5, 969.6, 969.7 or F11, F12, F14, F16 or F19 (ICD-10); illicit drug use, and/or a main or contributory diagnosis of 291, 303, 305.0, 357.5, 425.5, 535.3, 571.0-571.3, E860, E980+980 (ICD-9) or F10, K70, G621, I426, or K294 (ICD-10); alcohol related disorders.

Foster care among the biological parents after 1973 and among the children was identified in the Swedish Register of Children and Young Persons Subjected to Child Welfare Measures.

\section{Injury variables}

Information about hospital admissions because of injuries was collected from the Swedish Hospital Discharge Register 1987-2000, which includes 99\% of all hospital admissions in Sweden with up to six diagnoses at discharge. Quality evaluations have shown that an external cause diagnosis (e-diagnosis) is recorded in $97 \%$ of hospital admissions for injuries in this register.

Injuries were divided into the following seven categories based on ICD-9 for hospital discharges during 1987-96 and ICD-10 during 1997-2000.

- Fall: an e-diagnosis of 880-888 (ICD-9) or W00-W19 (ICD10).

- Poisoning: an e-diagnosis of 850-869 (ICD-9) or X40-X49 (ICD-10).

- Burn: an e-diagnosis of 890-899 or 924 (ICD-9) or X00X19 (ICD-10).

- Ingestion/intrusion of a foreign object: an e-diagnosis of 911915 (ICD-9) or W65-W84 (ICD-10).

- Traffic; an e-diagnosis of 819-826 (ICD-9) or V01-V79 (ICD-10).

- Violence; an e-diagnosis of 960-969 (ICD-9) or X85-Y09 (ICD-10).

- Child abuse: a main diagnosis of 995F (ICD-9) or T74 (ICD10).

\section{Statistical methods}

Multivariate analyses were conducted using the Cox regression of relative risk in hazard ratios of time to event with accidental injury (ICD9: E 800-928, ICD10: E V01-X59) and non-accidental injuries (violence and/or child abuse as defined above) as the two outcome variables. Each child was followed up prospectively in the registers from birth until their 7th birthday. Time to event was calculated with data on deaths from the National Cause of Death Register, date of hospital admission from the Swedish Hospital Discharge Register, and date of birth from the Swedish Medical Birth Registry.

Birth year was entered as a continuous variable in the regression models. Other sociodemographic variables were entered as category variables (using dummy variables) in the models: the maternal grandparents' country of birth was categorised into Sweden, Finland, Europe, (the rest of Europe, North America, Australia and New Zealand), nonEuropean (that is, the rest of the world), and mixed (one Swedish and one foreign born parent). Missing data were entered as a separate category in the analysis.

The variables in the Cox regression were entered in four steps to investigate possible mediating mechanisms: individual confounders (sex and year of birth) in the first model, variables representing confounders of the external environment of the child in the second model (type of community and housing), variables representing confounders of the social background of the mother in a third step (education, disposable income and social welfare benefits received by the grandmother, ethnicity) while variables representing mediators of the family environment in parental behaviour (psychiatric illness and substance misuse) and confounders and family composition (lone parent household and number of siblings) were entered in the final fourth model.

The SPSS software package, version 11.0, was used in all statistical analyses.

The Karolinska Institute's Ethical Committee approved the study.

\section{RESULTS}

We studied 800190 children who were born in Sweden between 1987 and 1993 during their first seven years of life. During the study period a total of 47126 (5.9\%) children were admitted to hospital for various kinds of unintentional and violent injuries. In the same period, 5282 deaths were reported, as 183 of which were caused by violence or accidents.

Table 1 shows parental sociodemographic characteristics in relation to maternal age at birth of the child. The most common maternal age at the birth of the child was 25-28 years, with only $2.7 \%$ of the mothers being teenagers: $0.4 \%$ aged $12-17$ and $2.3 \% 18-19$ years of age. Social situation differed between the teenaged women compared with the general maternal population. Compared with non-teenaged mothers, a considerably higher proportion of teenage mothers were primiparous and registered as single parents. Furthermore, the number of children in foster care was four to nine times greater in the teenage group than in the nonteenage group. Twice as many non-teenage mothers lived in one family houses, whereas teenage mothers often lived in rented flats.

The social background also differed between teenage and older mothers. For instance, the disposable income of teenage maternal grandmothers was twice as often in the lowest quartile, although the educational achievement did not differ substantially from that of the general population. Some $16 \%$ of teenage maternal grandmothers in the 18-19 age group, compared with $3.1 \%$ in the $25-28$ age group, had received social welfare payments and percentage of parents who had been admitted to hospital because of psychiatric illness and percentage of substance or alcohol misuse was three times higher in the teenage group. For example, in the youngest age 
Table 1 Sociodemographic characteristics in relation to maternal age at birth of child (data shown as numbers and percentages)

\begin{tabular}{|c|c|c|c|c|c|c|c|}
\hline Sociodemographic variables & $\begin{array}{l}\text { Number } \\
800190\end{array}$ & $\begin{array}{l}12-17 \\
3729\end{array}$ & $\begin{array}{l}18-19 \\
18097\end{array}$ & $\begin{array}{l}20-24 \\
180894\end{array}$ & $\begin{array}{l}25-28 \\
241550\end{array}$ & $\begin{array}{l}29-32 \\
196684\end{array}$ & $\begin{array}{l}33-55 \\
159236\end{array}$ \\
\hline \multicolumn{8}{|l|}{ Sex } \\
\hline Boy & 411042 & 51.5 & 51.2 & 51.3 & 51.4 & 51.6 & 51.2 \\
\hline Girl & 389148 & 48.5 & 48.8 & 48.7 & 48.6 & 48.4 & 48.8 \\
\hline \multicolumn{8}{|l|}{ Type of community } \\
\hline Big city & 254951 & 26.8 & 26.5 & 26.7 & 30.5 & 34.6 & 37.1 \\
\hline Town & 435656 & 57.4 & 58.0 & 58.2 & 55.7 & 52.6 & 50.1 \\
\hline Rural & 109583 & 15.8 & 15.5 & 15.1 & 13.8 & 12.8 & 12.8 \\
\hline \multicolumn{8}{|l|}{ Housing } \\
\hline Rented & 311126 & 57.5 & 57.3 & 48.9 & 39.7 & 33.4 & 30.5 \\
\hline Owned & 99269 & 5.4 & 8.4 & 12.1 & 13.4 & 12.8 & 11.4 \\
\hline One family house & 345334 & 24.7 & 24.3 & 32.5 & 41.8 & 48.7 & 53.0 \\
\hline Missing & 44461 & & & & & & \\
\hline Received welfare payments & 29540 & 26.0 & 16.3 & 6.6 & 3.1 & 2.0 & 1.4 \\
\hline Lone parent household & 28116 & 41.8 & 16.9 & 4.2 & 2.4 & 2.4 & 3.4 \\
\hline Child in foster home & 9594 & 9.1 & 3.9 & 1.5 & 0.9 & 0.8 & 1.2 \\
\hline \multicolumn{8}{|c|}{ Disposable income of grandmother } \\
\hline 1st quartile & 169430 & 59.8 & 46.2 & 26.9 & 19.6 & 21.6 & 31.6 \\
\hline 2nd quartile & 171096 & 20.3 & 25.5 & 26.5 & 24.0 & 23.8 & 26.8 \\
\hline 3rd quartile & 173118 & 11.2 & 17.1 & 25.7 & 28.1 & 26.0 & 20.9 \\
\hline 4th quartile & 169481 & 8.7 & 11.3 & 21.0 & 28.4 & 28.7 & 20.7 \\
\hline Missing & 117065 & & & & & & \\
\hline \multicolumn{8}{|l|}{ Education of grandmother } \\
\hline Primary & 354542 & 51.1 & 49.1 & 49.9 & 51.5 & 53.9 & 59.4 \\
\hline Secondary & 211448 & 38.2 & 39.3 & 36.7 & 32.3 & 28.8 & 25.9 \\
\hline University & 103174 & 10.6 & 11.6 & 13.4 & 16.2 & 17.4 & 14.8 \\
\hline Missing & 131026 & & & & & & \\
\hline \multicolumn{8}{|l|}{ Number of siblings } \\
\hline 0 & 328539 & 95.9 & 89.9 & 64.4 & 43.7 & 29.0 & 18.6 \\
\hline 1 & 281526 & 3.5 & 9.3 & 30.1 & 39.7 & 40.4 & 31.4 \\
\hline 2 & 130897 & 0.5 & 0.6 & 4.8 & 13.0 & 22.0 & 29.7 \\
\hline 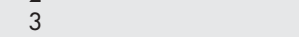 & 59228 & & 0.1 & 0.7 & 3.5 & 8.6 & 20.4 \\
\hline \multicolumn{8}{|l|}{ Country of birth of grandparents } \\
\hline Swedish & 628537 & 68 & 71 & 77 & 80 & 79 & 78 \\
\hline European & 44085 & 6.7 & 5.4 & 4.5 & 4.4 & 5.6 & 8.3 \\
\hline Non-European & 41491 & 8.0 & 9.0 & 6.1 & 4.7 & 4.8 & 5.0 \\
\hline Mixed & 86077 & 17.4 & 14.9 & 12.2 & 11.1 & 10.3 & 8.7 \\
\hline \multicolumn{8}{|l|}{ Maternal hospital admissions } \\
\hline Psychiatric disorder & 19397 & 6.7 & 4.6 & 2.6 & 2.2 & 2.2 & 2.6 \\
\hline Substance misuse & 6700 & 3.9 & 2.3 & 1.0 & 0.6 & 0.7 & 0.9 \\
\hline \multicolumn{8}{|l|}{ Paternal hospital admissions } \\
\hline Psychiatric disorder & 15949 & 4.7 & 3.6 & 2.4 & 1.7 & 1.7 & 2.1 \\
\hline Substance misuse & 16487 & 6.8 & 4.8 & 2.6 & 1.7 & 1.7 & 2.1 \\
\hline
\end{tabular}

group, $12-17$ years, $6.7 \%$ of the mothers had been treated in a psychiatric department, whereas the percentage was $2.2 \%$ among the women in the $25-28$ age group.

Table 2 shows the crude rates of hospital admissions for the five most common injuries in relation to sociodemographic parental and individual background factors. Children of teenage mothers had been admitted to hospital more often for all kinds of injuries, unintentional as well as violent, including child abuse, than those of older mothers.

Poisoning was the injury mechanism showing the greatest differences between the age groups, more than $2 \%$ of children whose mothers were $12-17$ years old compared with $0.8 \%$ among those of mothers over 34 .

Injuries were more common among children who lived in households where the maternal grandmother had received social welfare payments. Higher frequencies of hospital admissions were also found among children whose parents had been treated for either psychiatric disorders or substance misuse. In contrast, ethnicity, salary, housing, or education of the grandmother did not greatly influence the injury rates.

Hospital admission for unintentional as well as violent injuries were positively correlated with low maternal age in the multivariate analysis of hazard ratios in a step wise fashion, with the children of mothers aged 33-55 at the birth of the child having the lowest risks (tables 3 and 4 ). The relative risk (RR) for violent injuries was 2.7 and 2.5, respectively, for children with mothers aged 12-17 and 18-19 after adjustment for year of birth and sex (model 1 ) only compared with mothers aged 33-55. The RRs decreased to 2.0 and 2.3 after adjustment to the confounders (model 3 ) and to 1.9 and 2.2 after adjustment to the mediators (model 4). The relative risk (RR) for unintentional injuries was 1.6 and 1.5, respectively, for children with mothers aged 12-17 and 18-19 in model 1. The RRs decreased slightly to 1.4 in both teenage groups after adjustment to the confounders (model 3). Adding mediators to the model did not further change these estimates. It is noteworthy that the age group 20-24 years also had increased risks of injury compared with 33-55 year olds (RR 1.5 in model 1 for violent injuries and 1.2 for unintentional injuries) which were only marginally modified by introducing the confounders and mediators into the model.

In all, $5282(0.7 \%)$ children died during the study period, most of them, $2705(51 \%)$, because of perinatal disorders or others diseases $(45 \%)$. However, $145(2.7 \%)$ deaths were classified as being caused by unintentional injuries and 38 $(0.7 \%)$ by violent injuries. A significantly higher proportion of deaths were found among children with teenaged mothers. For instance, 213 (1\%) of children of teenaged mothers died compared with $5069(0.7 \%)$ in the general population, giving an crude RR of 1.5 ( 1.3 to 1.7) The proportion of children who died of violent injuries was $0.03 \%$ in the teenaged group and $0.004 \%$ in the overall population, which is equal to a RR of 6.7 
Table 2 Hospital admission (1/1000) by type of injury, at least once for children 0-6 years, in relation to sociodemographic indicators

\begin{tabular}{|c|c|c|c|c|c|c|c|c|c|}
\hline Sociodemographic variables & $\begin{array}{l}\text { Number } \\
800190\end{array}$ & $\begin{array}{l}\text { Fall } \\
24862\end{array}$ & $\begin{array}{l}\text { Poisoning } \\
7198\end{array}$ & $\begin{array}{l}\text { Burn } \\
2352\end{array}$ & $\begin{array}{l}\text { Traffic } \\
3238\end{array}$ & $\begin{array}{l}\text { Foreign } \\
\text { object } \\
3071\end{array}$ & $\begin{array}{l}\text { Violent } \\
\text { injuries } \\
572\end{array}$ & $\begin{array}{l}\text { Abuse } \\
93\end{array}$ & $\begin{array}{l}\text { All acciden } \\
47126\end{array}$ \\
\hline \multicolumn{10}{|l|}{ Maternal age at birth of child } \\
\hline $12-17$ & 3729 & 39.2 & 21.7 & 4.3 & 4.6 & 4.3 & 1.6 & 1.1 & 82.3 \\
\hline $18-19$ & 18097 & 39.3 & 12.3 & 5.1 & 6.5 & 4.8 & 1.5 & 0.6 & 76.6 \\
\hline $20-24$ & 180894 & 33.7 & 11.1 & 3.5 & 4.7 & 3.9 & 1.0 & 0.2 & 65.2 \\
\hline $25-28$ & 241550 & 32.0 & 8.9 & 2.8 & 4.2 & 3.9 & 0.6 & 0.1 & 59.5 \\
\hline $29-32$ & 196684 & 29.6 & 7.8 & 2.7 & 3.5 & 3.6 & 0.5 & 0.1 & 55.3 \\
\hline $33-55$ & 159236 & 27.3 & 7.6 & 2.6 & 3.5 & 3.9 & 0.6 & 0.1 & 52.7 \\
\hline \multicolumn{10}{|l|}{ Sex } \\
\hline Boys & 411042 & 34.5 & 10.2 & 3.5 & 4.7 & 4.5 & 0.8 & 0.1 & 66.7 \\
\hline Girls & 389148 & 27.4 & 7.7 & 2.3 & 3.4 & 3.1 & 0.6 & 0.1 & 50.7 \\
\hline \multicolumn{10}{|l|}{ Type of community } \\
\hline Big city & 254951 & 28.5 & 8.0 & 3.1 & 3.4 & 4.2 & 0.5 & 0.1 & 54.3 \\
\hline Town & 435656 & 32.6 & 9.4 & 2.9 & 4.2 & 3.7 & 0.8 & 0.1 & 61.1 \\
\hline Rural & 109583 & 30.8 & 9.7 & 2.7 & 5.0 & 3.4 & 0.8 & 0.1 & 60.9 \\
\hline \multicolumn{10}{|l|}{ Housing } \\
\hline Rented & 311126 & 32.3 & 9.0 & 3.3 & 4.2 & 3.9 & 0.9 & 0.2 & 60.6 \\
\hline Owned & 99269 & 30.7 & 7.7 & 2.2 & 3.5 & 3.9 & 0.6 & 0.1 & 55.2 \\
\hline One family house & 345334 & 30.1 & 9.2 & 2.6 & 4.0 & 3.7 & 0.5 & 0.0 & 57.9 \\
\hline Missing & 44461 & 31.0 & 10.7 & 4.2 & 4.5 & 4.4 & 1.1 & 0.3 & 63.2 \\
\hline \multicolumn{10}{|l|}{ Received welfare payments } \\
\hline Yes & 29540 & 37.3 & 12.5 & 4.4 & 5.7 & 4.2 & 1.3 & 0.2 & 72.2 \\
\hline No & 770650 & 30.8 & 8.9 & 2.9 & 4.0 & 3.8 & 0.7 & 0.1 & 58.4 \\
\hline \multicolumn{10}{|l|}{ Lone parent household } \\
\hline Yes & 28116 & 35.4 & 11.7 & 3.4 & 4.6 & 4.8 & 1.1 & 0.4 & 68.7 \\
\hline No & 710449 & 30.9 & 8.8 & 2.9 & 4.1 & 3.8 & 0.7 & 0.1 & 58.4 \\
\hline Missing & 61625 & 30.5 & 9.6 & 3.2 & 3.7 & 3.7 & 0.7 & 0.1 & 59.9 \\
\hline \multicolumn{10}{|l|}{ Child in foster home } \\
\hline Yes & 9594 & 41.8 & 21.4 & 6.4 & 6.6 & 4.6 & 9.8 & 4.3 & 90.6 \\
\hline No & 790596 & 30.9 & 8.8 & 2.9 & 4.0 & 3.8 & 0.6 & 0.1 & 58.5 \\
\hline \multicolumn{10}{|c|}{ Disposable income of grandmother } \\
\hline 1st quartile & 169430 & 32.4 & 9.9 & 3.2 & 4.2 & 3.9 & 0.7 & 0.1 & 62.2 \\
\hline 2nd quartile & 171096 & 32.2 & 8.9 & 2.7 & 4.4 & 3.9 & 0.7 & 0.1 & 60.0 \\
\hline 3rd quartile & 173118 & 31.3 & 9.1 & 2.6 & 3.6 & 3.7 & 0.7 & 0.1 & 58.6 \\
\hline 4th quartile & 169481 & 30.5 & 8.8 & 2.7 & 3.7 & 3.9 & 0.6 & 0.0 & 57.6 \\
\hline \multicolumn{10}{|l|}{ Education of grandmother } \\
\hline Primary & 354542 & 31.8 & 8.9 & 2.7 & 4.2 & 3.9 & 0.6 & 0.1 & 59.7 \\
\hline Secondary & 211448 & 32.4 & 9.6 & 2.8 & 4.1 & 3.8 & 0.8 & 0.1 & 60.8 \\
\hline University & 103174 & 30.2 & 9.3 & 2.9 & 3.3 & 3.7 & 0.7 & 0.0 & 57.7 \\
\hline \multirow{2}{*}{\multicolumn{10}{|c|}{ Number of siblings }} \\
\hline & & & & & & & & & \\
\hline 0 & 328539 & 29.5 & 8.3 & 2.8 & 3.6 & 3.4 & 0.7 & 0.1 & 55.1 \\
\hline 1 & 281526 & 32.8 & 9.0 & 2.8 & 4.2 & 4.0 & 0.7 & 0.1 & 61.0 \\
\hline 2 & 130897 & 30.7 & 9.9 & 3.2 & 4.4 & 4.3 & 0.7 & 0.1 & 61.0 \\
\hline 3 & 59228 & 32.2 & 10.6 & 3.9 & 5.0 & 4.9 & 1.0 & 0.2 & 65.2 \\
\hline \multicolumn{10}{|l|}{ Country of birth of grandparents } \\
\hline Swedish & 628537 & 31.7 & 9.1 & 2.7 & 4.0 & 3.8 & 0.7 & 0.1 & 59.5 \\
\hline European & 44085 & 27.1 & 8.1 & 3.8 & 3.8 & 3.1 & 0.9 & 0.3 & 52.2 \\
\hline Non-European & 41491 & 26.3 & 6.9 & 5.8 & 4.8 & 4.6 & 1.0 & 0.3 & 55.8 \\
\hline \multirow{2}{*}{\multicolumn{10}{|c|}{ Maternal psychiatric disorder }} \\
\hline & & & & & & & & & \\
\hline Yes & 19397 & 38.5 & 17.5 & 4.6 & 6.6 & 4.5 & 2.2 & 0.5 & 80.1 \\
\hline No & 780793 & 30.9 & 8.8 & 2.9 & 4.0 & 3.8 & 0.7 & 0.1 & 58.4 \\
\hline \multicolumn{10}{|l|}{ Maternal substance misuse } \\
\hline Yes & 6700 & 39.9 & 19.7 & 3.3 & 6.4 & 4.3 & 3.0 & 0.7 & 82.1 \\
\hline No & 793490 & 31.0 & 8.9 & 2.9 & 4.0 & 3.8 & 0.7 & 0.1 & 58.7 \\
\hline Paternal psychiatric disorder & & & & & & & & & \\
\hline Yes & 15949 & 38.1 & 14.2 & 3.7 & 6.1 & 4.0 & 1.4 & 0.4 & 75.1 \\
\hline No & 784241 & 30.9 & 8.9 & 2.9 & 4.0 & 3.8 & 0.7 & 0.1 & 58.6 \\
\hline Paternal substance misuse & & & & & & & & & \\
\hline Yes & 16487 & 37.8 & 12.4 & 3.7 & 5.8 & 4.4 & 2.0 & 0.7 & 72.7 \\
\hline No & 783703 & 30.9 & 8.9 & 2.9 & 4.0 & 3.8 & 0.7 & 0.1 & 58.6 \\
\hline
\end{tabular}

(2.8 to 16) after adjustment for age and sex. The corresponding proportion of deaths from unintentional injuries was $0.06 \%$ in the teenage group compared with $0.02 \%$ in the older groups, RR 3.5 (2.0 to 6.1 ).

\section{DISCUSSION}

In this study of a national cohort of pre-school children, we found that children of teenage mothers were at particular risk for morbidity and mortality. After adjustment for social background factors, children of teenage mothers had a $40 \%$ higher risk for unintentional injuries and a doubled risk for violent injuries compared with children of older mothers.

Previous international research has suggested poverty and low parental SES to be an important source of variation in childhood injuries. ${ }^{1-14}$ In this study, however, the unfavourable social conditions did not explain much of the higher risk of children of younger mothers even though the teenage mothers were socially disadvantaged. For instance, in the multivariate analysis, the risk increase for unintentional injuries decreased only from $60 \%$ to $40 \%$ after 
Table 3 Cox regression models for risk of at least one hospital admission for violent injuries

\begin{tabular}{lllll}
\hline $\begin{array}{l}\text { Maternal age } \\
\text { at birth of child }\end{array}$ & $\begin{array}{l}\text { Model 1 RR } \\
(95.0 \% \mathrm{Cl})\end{array}$ & $\begin{array}{l}\text { Model 2 RR } \\
(95.0 \% \mathrm{Cl})\end{array}$ & $\begin{array}{l}\text { Model 3 RR } \\
(95.0 \% \mathrm{Cl})\end{array}$ & $\begin{array}{l}\text { Model 4 RR } \\
\text { (95.0\% Cl) }\end{array}$ \\
\hline $12-17$ & $2.7(1.2$ to 6.1 & $2.2(1.0$ to 5.0$)$ & $2.0(0.8$ to 5.0$)$ & $1.9(0.8$ to 4.9$)$ \\
$18-19$ & $2.5(1.6$ to 3.8$)$ & $2.1(1.3$ to 3.2$)$ & $2.3(1.4$ to 3.7$)$ & $2.2(1.4$ to 3.6$)$ \\
$20-24$ & $1.7(1.3$ to 2.2$)$ & $1.5(1.2$ to 1.9$)$ & $1.5(1.1$ to 2.0$)$ & $1.5(1.1$ to 2.0$)$ \\
$25-28$ & $1.1(0.8$ to 1.4$)$ & $1.0(0.8$ to 1.3$)$ & $1.0(0.8$ to 1.4$)$ & $1.0(0.8$ to 1.3$)$ \\
$29-32$ & $0.9(0.7$ to 1.2$)$ & $0.9(0.7$ to 1.2$)$ & $0.9(0.7$ to 1.3$)$ & $0.9(0.7$ to 1.3$)$ \\
$33-55$ & 1 & 1 & 1 & 1 \\
\hline
\end{tabular}

Model 1 adjusted for sex and year of birth (child characteristics). Model 2 adjusted for sex, year of birth, type of community, and housing (external environment). Model 3 adjusted for sex, year of birth, type of community, housing, education of grandmother, income of grandmother in quartiles, welfare payments to grandmother, and ethnicity (social background). Model 4 adjusted for sex, year of birth, type of community, housing, education of grandmother, income of grandmother in quartiles, welfare payments to grandmother, ethnicity, lone parent household, alcohol, substance misuse, and/or psychiatric illness in parents (family environment).

Table 4 Cox regression models for risk of at least one hospital admission for unintentional injuries

\begin{tabular}{lllll}
\hline $\begin{array}{l}\text { Maternal age } \\
\text { at birth of child }\end{array}$ & $\begin{array}{l}\text { Model 1 RR } \\
(\mathbf{9 5 . 0 \%} \mathrm{Cl})\end{array}$ & $\begin{array}{l}\text { Model 2 RR } \\
\mathbf{9 5 . 0 \%} \mathbf{C l})\end{array}$ & $\begin{array}{l}\text { Model 3 RR } \\
(\mathbf{9 5 . 0 \%} \mathrm{Cl})\end{array}$ & $\begin{array}{l}\text { Model 4 RR } \\
\mathbf{9 5 5 . 0 \% ~ C l )}\end{array}$ \\
\hline $12-17$ & $1.6(1.4$ to 1.8$)$ & $1.6(1.4$ to 1.8$)$ & $1.4(1.3$ to 1.6$)$ & $1.4(1.2$ to 1.6$)$ \\
$18-19$ & $1.5(1.4$ to 1.6$)$ & $1.4(1.4$ to 1.5$)$ & $1.4(1.3$ to 1.5$)$ & $1.4(1.3$ to 1.5$)$ \\
$20-24$ & $1.2(1.2$ to 1.3$)$ & $1.2(1.2$ to 1.3$)$ & $1.2(1.2$ to 1.2$)$ & $1.2(1.2$ to 1.2$)$ \\
$25-28$ & $1.1(1.1$ to 1.2$)$ & $1.1(1.1$ to 1.2$)$ & $1.1(1.1$ to 1.1$)$ & $1.1(1.1$ to 1.1$)$ \\
$29-32$ & $1.0(1.0$ to 1.1$)$ & $1.0(1.0$ to 1.1$)$ & $1.0(1.0$ to 1.1$)$ & $1.0(1.0$ to 1.1$)$ \\
$33-55$ & 1 & 1 & 1 & 1 \\
\hline
\end{tabular}

Model 1 adjusted for sex and year of birth (child characteristics). Model 2 adjusted for sex, year of birth, type of community, and housing (external environment). Model 3 adjusted for sex, year of birth, type of community, housing, education of grandmother, income of grandmother in quartiles, welfare payments to grandmother, and ethnicity (social background). Model 4 adjusted for sex, year of birth, type of community, housing, education of grandmother, income of grandmother in quartiles, welfare payments to grandmother, ethnicity, lone parent household, alcohol, substance misuse and/or psychiatric illness in parents (family environment).

adjustments for all social factors in the youngest age group, $12-17$ years.

Although registers give a broad range of information, many aspects of life cannot be elucidated from these sources. Thus, the increased risk of injuries among the children of teenage mothers could have several other explanations that we could not control for in the regression analysis. Firstly, the accumulation of disadvantaged background factors indicates social exposure deprivation already before pregnancy among parenting teenagers. The high proportion of serious alcohol and illicit drug addiction also indicates that the average use of alcohol and illicit drugs is higher among teenage than adult parents and confirms a high risk pattern in this group. ${ }^{15}{ }^{16}$ Thus, teenage parenting should be considered as part of a complex pattern of risk taking behaviour, including school problems, misuse of alcohol and illicit drugs, and psychiatric morbidity.

Secondly, previous studies have shown that a lack of social support and social isolation are mediating factors in childhood injuries. ${ }^{17}{ }^{18}$ In this study nearly $25 \%$ of teenage mothers, compared with $5 \%$ of non-teenage mothers, were registered as single parents. Although all injuries were more prevalent among the children of lone mothers, this did not explain the increase in risk in the regression model. Thus it is undeterminable whether the presence of fathers of children born to teenage mothers influences the rates of injuries. Our results, together with those of previous studies, indicate that the fathers of children born to teenage mothers are often involved in problem behaviour and criminality, which might have adverse consequences. ${ }^{19-22}$ However, other studies show that the presence of such fathers generally, but not uniformly, has a positive impact on the health and development of the children. ${ }^{23} 24$

Lastly, some proportion of the raised risks among children of teenage mothers can probably be explained by the nature of adolescence. Adolescence is a normal maturational crisis and a period when independence and experimentation is a natural part of development. However, parenting teenagers must simultaneously face a variety of situational crises- that is, pregnancy and parenthood, each of them associated with some degree of stress. This, together with a lack of life experience, knowledge of child development, limited financial resources, and psychological immaturity, may reduce the ability of teenage mothers to cope adequately with parenting demands, to engage in injury preventive behaviour, and to protect their children from physical trauma. ${ }^{25}$

One particularly important finding was the doubled risk of hospital admissions and the six times higher risk of mortality attributable to violent injuries among the children of teenage mothers compared with those of non-teenage mothers. This finding is in line with some previous international research. ${ }^{26}{ }^{27}$ Yet, the results must be interpreted with caution. During the 12 year study period, only 572 cases of violent injury were admitted to hospital and 93 of these were diagnosed as child abuse. In addition, 38 children died due to

\section{Key points}

- In this national cohort study, children of teenage mothers were at particular risk for morbidity and mortality because of unintentional and violent injuries.

- Although teenage mothers had a disadvantaged social background, unfavourable social conditions did not explain much of the increased risk.

- Maternal age is an important determinant of injuries in pre-school children in Sweden. 


\section{Policy implications}

- Young parents should be given priority in injury prevention programmes.

- A successful intervention with a demonstrated effect on population health is, however, unlikely as the teenage pregnancy rate in Sweden is as low as $2.7 \%$.

violence. As only the more severe injuries are treated in hospital, the cases of child abuse are probably underreported among children in the whole population. Placement in foster care was associated with very high rates of violent injury and child abuse. However, we are unable to determine if the injury or abuse occurred during the stay in foster care or elsewhere. Hence it cannot be ascertained whether foster care protects from or exposes children to violence. There is a need for more research into the consequences and the quality of care of children and teenagers in foster care.

\section{Methodological considerations}

The important strength of this study is the large study population made possible by the high quality and wide coverage of the Swedish national registers. The use of hospital discharge records means that the measure of health is not biased by self reporting, and covers the most serious morbidity outcomes. However, register data do not include information about the severity of injury; nor do they include information on where an injury took place or in whose care the child was. If the children of teenage parents are more likely to be admitted to hospital compared with those of other parents, the risk will be overestimated. That would be the case if young parents are more inclined to seek hospital care or if they are more watched/observed by social workers or health staff than older parents are, and therefore their children are brought to hospital more often than those of older parents. It is also possible that the decision taken by the physician in the emergency room to admit or not admit a child for certain injuries is influenced by the age of the parents. As the mortality rates were similar, or even higher, than the rates based on hospital admissions, this seems to be an unlikely source of bias in this study.

\section{Authors' affiliations}

C Ekéus, K Christensson, Department of Public Health Sciences, IHCAR, Karolinska Institute, Sweden

A Hiern, Centre for Epidemiology, National Board of Health and

Welfare, Stockholm, Sweden and Department of Children's and

Women's Health, Uppsala University, Sweden

Funding: the Swedish Victim Compensation and Support Authority financially supported the study.

Conflicts of interest: none declared.

\section{REFERENCES}

1 Scholer SJ, Mitchel EF, Wayne AR. Predictors of injury mortality in early childhood. Pediatrics 1997; 100:342-7.

2 Roach JO. Injuries kill over 20000 children a year in developed countries. BMJ 2001;322:317.

3 Peridou E. Childhood injuries in the European Union: Can epidemiology contribute to their control? Acta Paediatr 2000;89:1244-9.

4 Otterblad Olausson P, Haglund B, Ringbäck-Weitoft G, et al. Teenage pregnancy and long-term socioeconomic consequences: a case study in Sweden. Fam Plann Persp 2001;33:70-4.

5 Otterblad Olausson P. Teenage childbearing. Pregnancy outcomes and longterm consequences for the mothers. [MD Thesis.] Stockholm: Karolinska Institute, 2000.

6 Ekéus C, Christensson K. Socioeconomic characteristics of fathers of children born to teenage mothers in Stockholm, Sweden. Scand J Public Health 2003;31:73-6.

7 Edgardh K. Sexual behaviour and early coitarche in a national sample of 17 year-old Swedish boys. Acta Paediatr 2002;91:985-91.

8 Woodward L, Fergusson DM. Early conduct problems and later risk of teenage pregnancy in girls. Dev Psychopathol 1999;11:127-41.

9 Springarn RW, DuRant R. Male adolescent involved in pregnancy: associated health risk and problem behaviours. Pediatrics 1996;98:262-7.

10 Statistics Sweden. Socio-economic classification (SEI). Stockholm: Statistics Sweden, 1982.

11 Hiern A, Bremberg S. Social aetiology of violent deaths in Swedish children and youth. J Epidemiol Community Health 2002;56:688-92.

12 Hiern A, Ringbäck-Weitoft G, Andersson R. Socio-demographic risk factors for home-type injuries in Swedish infants and toddlers. Acta Paediatr $2001 ; 90: 61-8$.

13 Faelker T, Pickett W, Brison RJ. Socioeconomic differences in childhood injury: a population based epidemiologic study in Ontario Canada. Injury Prevention 2000;6:203-8.

14 Rivara FP. Unintentional injuries. The epidemiology of childhood disorders. Oxford: Oxford University Press, 1994:369-411.

15 Lee MC, Lee SH, Chou MC. Association of risk-taking behaviours with adolescent childbearing. J Formos Med Assoc 2001;100:533-8.

16 Flanagan $P$, Kokotalio P. Adolescent pregnancy and substance abuse. Clin Perinatolo 1999;26:185-200.

17 Ringäck Weitoft G, Hjern A, Haglund B, et al. Mortality, severe morbidity, and injury in children living with single parents in Sweden: a populationbased study. Lancet 2003;361:289-95.

18 Engström K, Diderichsen F, Laflamme L. Socioeconomic differences in injury risk in childhood and adolescence: a nation-wide study of intentional and unintentional injuries in Sweden. Injury Prevention 2002;8:137-42.

19 Stouthamer-Loeber M, Wei EH. The precursors of young fatherhood and its effect on delinquency of teenage males. $J$ Adolesc Health 1998;22:56-65.

20 Elster $\mathbf{A B}$, Lamb $M$, Peters $L$, et al. Judicial involvement and conduct problems of fathers of children born to adolescent mothers. Pediatrics 1987;79:230-4.

21 Pierre N, Shrier LA, Emans SJ, et al. Adolescent males involved in pregnancy: associations of forced sexual contact and risk behaviours. J Adolesc Health 1998;23:364-9.

22 Guagliardo MF, Huand Z, Dángelo L. Fathering pregnancies: marking health-risk behaviors in urban adolescents. J Adolesc Health 1999;24:10-15.

23 Kelly L. Adolescent mothers: what factors relate to level of preventive health care sought for their infants? J Pediatr Nursing 1995; 10:105-13.

24 Roye CF, Balk SJ. The relationship of partner support to outcomes for teenage mothers and their children: a review. J Adolesc Health 1996;19:86-93.

25 Stevens-Simon C, Nelligan D, Kelly L. Adolescents at risk for mistreating their children. Part I: Prenatal identification. Child Abuse Negl 2001;6:737-51.

26 Zelenko MA, Huffman L, Lock J, et al. Poor adolescent expectant mothers: can we assess their potential for child abuse? J Adolesc Health $2001 ; 29: 271-8$.

27 Dukewich T, Borkowski JG, Whitman T. Adolescent mothers and child abuse potential: an evaluation of risk factors. Child Abuse Negl 1996;20:1031-47. 